\title{
A Progressive Multilevel Model for Selecting Medical Tourism Destinations: A Qualitative Study
}

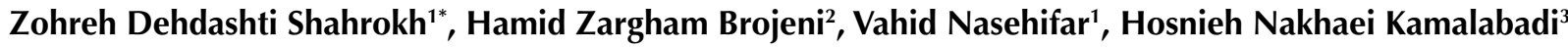 \\ ${ }^{1}$ Marketing Management Department, Faculty of Management \& Accounting, Allameh Tabataba'i University, Tehran, \\ Iran \\ ${ }^{2}$ Tourism Management Department, Faculty of Management \& Accounting, Allameh Tabataba'i University, Tehran, Iran \\ ${ }^{3}$ Allameh Tabataba'i University, Tehran, Iran
}

Corresponding Author: Zohreh Dehdashti Shahrokh, Ph.D., Associate Professor, Marketing Management Department, Faculty of Management \& Accounting, Allameh Tabataba'i University, Tehran, Iran. Tel: +98-2122254573, Email: zdehdashti33@gmail.com

Received May 3, 2017; Accepted June 21, 2017; Online Published June 30, 2017

\begin{abstract}
Introduction: The overall objective of this study was to design a progressive multilevel model using the Delphi method for selecting a medical tourism destination which includes 3 levels of decision making: the destination country, then the destination city, and finally, the healthcare center in the selected city. This model can be used as a new area of research for further planning in Iran's growing medical tourism industry.

Methods: This study is a descriptive, practical research using a qualitative approach. In the preliminary stage, an extensive review of the literature was performed, and the Delphi method was used to identify factors influencing the selection of Iran as a medical tourism destination. Experts participating in the Delphi panel reached consensuses after applying 3 rounds. Analysis of the data from the Delphi panel resulted in the construction of a multilevel model for selecting a medical tourism destination.

Results: The outcome of this research was a constructed multilevel model for selecting a medical tourism destination. The model indicates all factors influencing the selection of each level of destination. It also includes 2 stages of decision making (medical tourism and information search), which come before the selection of 3 levels of destination.

Conclusion: Iran's political and economic situations after the imposition of sanctions and its problems in providing banking services for medical tourists are among the factors influencing medical tourists not to choose Iran as their destination. Government support, planned promotional activities, and $\mathrm{JCl}$ accreditations could increase the attraction of medical tourists to Iran.

Keywords: Medical tourism, Multilevel model, Iran
\end{abstract}

Citation: Dehdashti Shahrokh Z, Zargham Brojeni H, Nasehifar V, Nakhaei Kamalabadi H. A progressive multilevel model for selecting medical tourism destinations: a qualitative study. Int J Travel Med Glob Health. 2017;5(2):60-68. doi:10.15171/ijtmgh.2017.12.

\section{Introduction}

Medical tourism is the act of traveling abroad to receive medical treatment. ${ }^{1}$ The popularity of medical travel is mostly due to the need for access to expertise, technology, and high quality healthcare services, ${ }^{2}$ high medical costs, ${ }^{2,3}$ unavailability of treatments in a home country due to legal/ cultural reasons, ${ }^{4}$ long waits in queues for treatment, and family care support. ${ }^{1}$

Medical tourism, a rapidly growing industry, is known as a revenue generating source. ${ }^{5,6}$ India, Malaysia, Singapore, Jordan, Turkey, South Africa, the Philippines, and Greece are promoting their medical tourism industries. ${ }^{1}$ In the Middle East, Iran is known as a main hub for medical tourism and benefits from its potentials in this field, i.e. its expert and well-known physicians, state-of-the-art medical technology, advanced medical research, and the existence of natural and cultural tourist attractions. ${ }^{7}$ Despite other medical destinations, Iran has the competitive advantage of having different cities as medical tourism hubs, which makes decision making easier for medical travelers; they can choose the city nearest their home country. Medical tourism hubs in Iran include Tehran, Isfahan, Shiraz, Ahvaz, Tabriz, Mashhad, and Yazd, which cover almost all neighboring countries. For instance, patients from Azerbaijan choose Tabriz because of distance and language similarity, and Iran's eastern neighbors choose Mashhad or Yazd. Jabbari et al introduced Shiraz, located in the south of Iran, as the first destination for medical travelers from Persian Gulf and Arab countries. Medical centers equipped with modern medical equipment and staffed by expert physicians and medical staff in both public and private hospitals, historical tourist attractions, clement weather, and its proximity to other Persian Gulf

Copyright $(\odot 2017$ The Author(s). This is an open access article distributed under the terms of the Creative Commons Attribution License (http:// creativecommons.org/licenses/by/4.0), which permits unrestricted use, distribution, and reproduction in any medium, provided the original work is properly cited. 
countries have increased the popularity of Shiraz as a medical destination in Iran. ${ }^{8}$

This paper seeks to model all of the factors influencing medical tourists' selection of Iran as their destination. Previously, Smith and Forgione presented a 2-stage model that included factors affecting American patients' decisions in seeking healthcare services globally. Their model suggests that there are 2 stages in a patient's decision-making process: first, the patient chooses the destination country, and in the next stage s/he considers the international healthcare center; various factors influence decision-making in each stage. ${ }^{9}$ Hueng et al proposed a supply-and-demand model for medical tourists which included 3 levels of decision-making: selecting the destination country, the healthcare center, and the doctor. ${ }^{10}$ Fetscherin and Stephano constructed a multidimensional model for conceptualizing the medical tourism index. They suggested that the medical tourism index include 4 key dimensions: (1) the country environment, (2) the tourism destination, (3) the medical tourism costs, and (4) the quality of the medical facility and services. The medical tourism index measures key factors in a destination's attractiveness. However, the model lacks a "smaller subdivision to allow for benchmarking efforts to improve medical tourism index in multiple cities in one country." Therefore, considering the gap in literature regarding choosing a destination city and the lack of a medical tourism model for Iran, the researchers in this study propose a model that includes 3 levels of decisionmaking: first, choosing Iran as the destination country; second, choosing the destination city; and third, selecting the healthcare center. Since there are multiple cities in Iran that attract medical travelers, the second level for the medical tourist is selecting the destination city. The constructed model can be used by other countries such as Columbia and Turkey which have multiple cities that provide medical tourism services.

The proposed model is the result of this qualitative study that applied 3 rounds of the Delphi method. Multiple factors that impact a patient's choice in each level of decisionmaking were obtained from a literature review and are briefly explained in the following. All of the following factors along with their mentioned variables are included in the structured part of the Delphi questionnaire.

\section{Features of the Destination Country}

Previous studies indicate that factors influencing a medical tourist's decision on a medical destination are: economic condition, political situation, ${ }^{11}$ medical tourism infrastructure, government support, ${ }^{11}$ and cultural factors. ${ }^{12}$ This study adds personal factors ${ }^{13}$ as another influencing factor to choice of country. All of these factors with their variables are explained briefly:

Economic condition: Today, Iran is experiencing a better economic condition; due to a "thawing of relations between the country and the rest of the world, Iran seems to be poised for a huge economic leap forward." 14 This could lead to the expansion of Iran's medical tourism industry which was negatively affected by economic instability, rapid alterations in currency exchange rates, and high inflation rates in previous years. ${ }^{6,15}$ However, low medical and accommodation costs ${ }^{16}$ compared with those of regional countries give Iran a competitive advantage in attracting medical tourists.

Political condition: One major constraint for the medical tourism industry is the destination's political condition. ${ }^{11}$ The political situation presented an "unsuitable image of Iran in international societies," which affected the attraction of medical tourists and moved this market towards competitor countries in the region. ${ }^{6,16}$

Medical tourism infrastructure: Iran benefits from a high quality medical tourism infrastructure including wellknown, expert physicians with international medical degrees; the availability of treatments not possible in neighboring countries such as infertility treatments, plastic surgeries, and implantation; modern pharmaceutical companies with the technology to produce medicine in Iran $^{6}$; modern medical equipment; famous medical research centers; and inexpensive and high-quality medical services. ${ }^{8}$

Cultural factors: Medical tourism destinations usually attract patients from countries with similar cultures or languages. ${ }^{17}$ Generally, Muslims prefer to choose countries that have an Islamic culture ${ }^{17}$; therefore, Iran as an Islamic country is the destination for medical tourists from neighboring Muslim countries, ${ }^{6}$ especially from Shi'a Muslim countries. ${ }^{4}$

Government support: Today, governments play a significant role in introducing their medical tourism industry. The governments of some countries, such as South Africa, India, Malaysia, Thailand, and Singapore, market themselves as "global health destinations" through different promotional activities $^{18}$ and support the medical tourism industry by providing various options like "long repayment constructive loans"15 or tax incentives to healthcare centers as motivation to attract more medical tourists. The rapid preparation of visas for medical tourists could also be a form of government support. $^{18}$

Personal factors: Personal factors mainly comprise a patient's age, income level, insurance status, and health status. Income level and insurance status makes patients "unable to afford the cost of care" in their home countries and motivates them to travel abroad for medical treatments. ${ }^{3,13}$

\section{Features of the Destination City}

At the level of city selection, the factors proven to influence the tourist's choice are tourist attractions, geographical factors, micro-cultural factors, and familiarity.

Tourism attractions: Generally, 2 groups of resources are involved in making a destination competitive. The first group comprises natural, heritage, and cultural attractions which are specific attributes of the selected city; this group is known as endowed resources. The second group, known as created resources, consists of services offered to tourists including accommodations, food and beverages, entertainment, and shopping. ${ }^{19}$ Studies have indicated that a large portion of medical tourists in China, India, and Jordan enjoyed their time visiting local culture attractions, shopping, and sightseeing. ${ }^{20}$

Geographical factors: Iran enjoys a good geographical position near countries that generate medical tourists. It is easily accessible by ship, airplane, train, and $\operatorname{car}^{6}$ and has pleasant weather (4 seasons) compared with other Persian Gulf countries.

Micro-cultural factors (communication): Medical tourists traveling to Iran usually select the city with the most cultural 
similarities. For instance, Ahvaz is chosen by Arab patients from Iraq, Kuwait, and other Persian Gulf countries ${ }^{21}$ because of its Arabic culture and language; patients from Azerbaijan usually travel to Tabriz because of its proximity and the language similarity (Turkish).

Familiarity: The opportunity to visit friends and relatives to benefit from their caring support ${ }^{1}$ or the patient's previous visits to a chosen city can also have a significant impact.

\section{Features of the Destination Healthcare Center}

Smith and Forgione's conceptual model suggests that accreditation, quality of care, physician training, and cost are factors influencing the selection of a medical facility. ${ }^{9}$ Heung et al suggest the same factors for choosing a medical center, except reputation is considered instead of quality of care. ${ }^{10}$ In this research, accreditation is considered as a sign of quality. This study considers promotional activities (provided by the medical center), quality, medical staff, treatment variety, and facilitators to be significant factors in selecting a healthcare center.

Promotional activities: Promotional efforts help healthcare centers introduce themselves in the global market, and this marketing strategy is used today by a large number of international healthcare providers. ${ }^{22}$ A healthcare center's promotional activities can include promoting doctors, providing specialized treatments, and having a brand. ${ }^{10}$

Quality: Research has indicated that quality is the most important factor in destination choice, ${ }^{12,23}$ while a medical traveler's main purpose in choosing a destination is to receive high quality medical services at affordable prices. ${ }^{12}$ Actually the "quality of the healthcare center" (including international accreditation, ${ }^{3,24}$ hospital brand, ${ }^{3,11}$ and modern medical equipment ${ }^{23}$ ) and the "quality of care services" provided by the medical staff (physicians and personnel) are the 2 major factors for quality in the healthcare industry. ${ }^{13}$

Medical Staff: There are 5 important factors about medical staff that affect medical travelers' hospital choice. These factors include physicians' reputations, ${ }^{10}$ physicians' expertise and specialties, ${ }^{11}$ physicians' international degrees, ${ }^{3,12}$ experienced and high quality nursing staff, and the ability of the medical staff to speak English ${ }^{11}$ or the existence of translators in the healthcare center.

Treatment variety: The variety of medical and special treatments provided in a healthcare center impacts a patient's decision. Some healthcare centers, like Basir Ophthalmology Clinic, only provide eye-related medical services, while others provide a variety of medical services.

Facilitators: Medical tourism facilitators play a significant role in marketing and selling medical services around the globe. In addition to finding appropriate hospitals, they also arrange all the pre- and post-travel processes, including transportation, accommodations, medical treatments, translators, and even visits to the destination's tourist attractions. ${ }^{25,26}$ The Delphi questionnaire contains 3 levels of destination selection and includes multiple influencing factors along with their variables, all of which were explained above. To developing Iran's model for medical tourism destination selection, all of these influencing factors were presented in the Delphi questionnaire and were evaluated by the Delphi panel.

\section{Methods}

This research is a descriptive, practical, and qualitative study based on the Delphi method. Upon analysis of the existing literature and the employment of a qualitative approach using the Delphi method in 3 rounds, the outcome provided the influencing factors in identifying medical tourism destinations. These factors were implemented and ultimately a multilevel model was constructed. The Delphi method was chosen to decrease different ranges of opinion in responses and achieve a group consensus for each topic. This method is used particularly when objective data is unattainable or there is a lack of empirical evidence. ${ }^{27}$ The most important characteristics of the Delphi technique as a flexible method are its "structured questioning, iteration, controlled feedback, and anonymity of responses."28

The current study aimed to design a model for Iran's medical tourism that includes 3 levels of decision-making by answering the question of what important factors impact medical tourists' selection of Iran as a destination country. The resulting model proposes 3 steps: Selecting Iran as the destination country in the first step, selecting the destination city in the second step, and finally, selecting the healthcare center. This model can also be used for other destinations that offer medical services in multiple cities.

The qualitative research design consisted of Iranian experts in the medical tourism industry, including academic researchers and university professors with special experience in medical tourism; managers and the staff of a healthcare center's medical tourism sector; and travel agents who have experience in persuading medical tourists to choose Iran. Facilitators were asked to participate, but because none of them had legal permission from the Tourism and Cultural Organization, they declined to participate in the panel. Using the Delphi method, a structured questionnaire was designed that included all of the identified influencing factors. This questionnaire was distributed among Iranian experts in the medical tourism industry in 3 rounds from February to June, 2016. It contained 4 descriptive questions and 58 structured questions scored on a 5 -point Likert scale ( $1=$ very unimportant, 2 =less important, 3 =average, $4=$ important, $5=$ very important) and 2 open-ended questions. The 58 structured questions included all the influencing factors and their variables gathered from the literature review which are explained briefly in the introduction. Panel members were selected through judgmental and snowball sampling, and the questionnaire was delivered to them physically or via email. Only 20 of the 50 chosen experts participated in the Delphi panel (40\% participation) in the first round. After analyzing the data from the first round, the mean score of each question was calculated, and the answers to the open questions were analyzed using the content analysis method. The second questionnaire sent to the panel members contained 2 new columns for collecting feedback: (1) the mean of the experts' responses to each question, and (2) each participant's opinion in the first round. The second questionnaire also contained 13 new questions (variables) based on the experts' suggestions in round one. Eighteen members of the Delphi panel participated in the second round (90\% participation). Consensus was reached for all questions of the questionnaire after conducting 
2 rounds of Delphi, except for those 13 questions added to the second questionnaire. Therefore, panel members were asked to answer these questions for the third time to reach a consensus. Fifteen questionnaires were returned $(83 \%$ participation).

The validity of this study was confirmed as the Delphi questionnaire only contained questions that had been extracted from previously published studies and submitted to professors and experts in the field of medical tourism. The software SPSS 23 was used for all statistical tests. The reliability was obtained by Cronbach a for all rounds of Delphi (Table 1). Significant results were gained for all items in the Kolmogorov-Smirnov (K-S) test of normality (Table 2). In this test, the null hypotheses are defined as $H_{0}$ : The population has a normal probability distribution. The rejection rule is defined as Reject $H_{0}$ if the $P$ value $<\alpha$, where $\alpha=0.05{ }^{29}$ Since the results indicated that the data had no normal distribution, the nonparametric tests Sign and Wilcoxon of paired dependent samples were performed for the data collected from 2 rounds to identify whether a consensus was reached or iteration with feedback should be continued (columns 6 and 7 of Table 2). Both tests involved the same null hypothesis assuming there were no differences between the means of the 2 populations. ${ }^{30}$ If the calculated $P$ value obtains a value lower than 0.05 , it can be concluded that the means of the paired dependent samples are different and the iteration with feedback must be continued. Otherwise, the null hypothesis is accepted, and a consensus is reached; thus, there is no need to continue the Delphi rounds. After 3 rounds of running the Delphi method, a consensus was reached.

\section{Results}

This study purposed to construct a multilevel model including various influencing factors in selecting Iran as the medical tourist's destination country, selecting the destination city, and selecting the medical center. By reviewing published literature in this subject area, all the influencing factors with their relative variables were first identified. Then, the identified factors and their variables were used to design the Delphi questionnaire.

To gather the opinions of experts, the Delphi questionnaire was sent to 50 experts in medical tourism, but only 20 experts participated in the Delphi panel. Among these 20 participants, 12 were female $(60 \%)$ and 8 were male $(40 \%)$. Six members (30\%) of the panel had bachelor's degrees, 8 (40\%) had master's degrees ( 3 of them were PhD students), 5 members had a $\mathrm{PhD}(25 \%)$, and 1 member was a physician (5\%). All respondents had more than 3 years of experience in the field of medical tourism.

The results of the reliability test for the questionnaires distributed in the first and second rounds of the Delphi method are shown in Table 1. The results indicate that the calculated Cronbach a for each influencing factor was higher than 0.7, which indicates the questionnaire is reliable.

By analyzing the panel members' responses to the openended questions in the first round, it was determined that 13 questions needed to be added to the second questionnaire. In analyzing these questions, 2 significant influencing factors ("social security" and "banking services") were explored and added to the first level (selecting Iran). The other explored variables (indicated with stars) were added to the existing influencing factors in all 3 levels of the model (Table 2).

Table 2 includes the calculated means for each question in both the first and second rounds of Delphi. This table also shows the results of the K-S test, which indicated that the $P$ value $<0.05$; thus, the data had no normal distribution. Hence, the Sign and Wilcoxon nonparametric tests were conducted to verify whether a consensus was reached. For both nonparametric tests, an interval confidence of $95 \%$ was assumed for the difference between the 2 population means. ${ }^{29}$ The null and alternative hypotheses were stated as follows: $H_{0}: \mu_{1}-\mu_{2}=0$

Table 1. Results of Reliability Tests for 2 Rounds of Delphi Method

\begin{tabular}{|c|c|c|c|}
\hline Levels & Influencing Factors & 1st Round Chronbach $\alpha$ & 2nd Round Chronbach $\alpha$ \\
\hline \multirow{9}{*}{$\begin{array}{l}\text { Selecting Iran as the destination } \\
\text { country }\end{array}$} & Medical tourism infrastructure & 0.79 & 0.76 \\
\hline & Cultural factors & 0.78 & 0.77 \\
\hline & Political situation & 0.84 & 0.78 \\
\hline & Economic situation & 0.81 & 0.79 \\
\hline & Personal factors & 0.75 & 0.74 \\
\hline & Promotional activities & 0.85 & 0.86 \\
\hline & Government support & 0.74 & 0.72 \\
\hline & Social factors ${ }^{\mathrm{a}}$ & - & 0.89 \\
\hline & Banking services $^{\mathrm{a}}$ & - & 0.79 \\
\hline \multirow{4}{*}{ Selecting the destination city } & Tourism attractions & 0.88 & 0.85 \\
\hline & Ease of access & 0.84 & 0.81 \\
\hline & Micro cultural factors & 0.79 & 0.77 \\
\hline & Familiarity & 0.77 & 0.76 \\
\hline \multirow{5}{*}{ Selecting the healthcare center } & Promotional activities & 0.93 & 0.90 \\
\hline & Facilitators & 0.82 & 0.80 \\
\hline & Quality & 0.86 & 0.84 \\
\hline & Medical staff & 0.94 & 0.95 \\
\hline & Treatment variety & 0.85 & 0.86 \\
\hline Total & & 0.91 & 0.89 \\
\hline
\end{tabular}

${ }^{a}$ Explored influencing factors obtained from the Delphi panel. 
Table 2. Results of Kolmogorov-Smirnov Test and Nonparametric Sign and Wilcoxon Tests for the First and Seconds Rounds

\begin{tabular}{|c|c|c|c|c|c|c|}
\hline Factors & Variables & $\begin{array}{l}\text { 1st Round } \\
\text { Means }\end{array}$ & $\begin{array}{l}\text { 2nd Round } \\
\text { Means }\end{array}$ & K-S test & $\begin{array}{l}P \text { Value in } \\
\text { Sign Test }\end{array}$ & $\begin{array}{c}P \text { Value in } \\
\text { Wilcoxon Test }\end{array}$ \\
\hline \multirow{4}{*}{$\begin{array}{l}\text { Medical } \\
\text { tourism } \\
\text { infrastructure }\end{array}$} & Modern medical equipment and facilities & 4.65 & 4.50 & 0.000 & 0.435 & 0.257 \\
\hline & Advanced technology and medical research & 4.55 & 4.72 & 0.000 & 1.000 & 0.739 \\
\hline & Availability of medical treatments in Iran & 4.25 & 4.33 & 0.000 & 1.000 & 1.00 \\
\hline & Adequate tourism infrastructure & 4.25 & 4.22 & 0.000 & 0.727 & 0.480 \\
\hline \multirow{5}{*}{$\begin{array}{l}\text { Cultural } \\
\text { factors }\end{array}$} & Iran's Islamic culture & 4.65 & 4.17 & 0.000 & 0.204 & 0.564 \\
\hline & $\begin{array}{l}\text { Cultural, historical, and religious relations with neighboring } \\
\text { countries }\end{array}$ & 4.50 & 4.33 & 0.000 & 0.125 & 0.069 \\
\hline & Halal food and beverages & 4.45 & 4.05 & 0.000 & 0.109 & 0.152 \\
\hline & Religious similarity for Shi'a medical tourists ${ }^{b}$ & - & 4.11 & - & - & - \\
\hline & Tendency for pilgrimages for Shi'a medical tourists ${ }^{b}$ & - & 4.05 & - & - & - \\
\hline \multirow{2}{*}{$\begin{array}{l}\text { Political } \\
\text { factors }\end{array}$} & Political stability & 4.35 & 4.72 & 0.000 & 0.508 & 0.248 \\
\hline & Iran's image in international societies & 4.35 & 4.33 & 0.000 & 0.727 & 0.480 \\
\hline \multirow{5}{*}{$\begin{array}{l}\text { Economic } \\
\text { conditions }\end{array}$} & Low cost of medical services & 4.50 & 4.72 & 0.000 & 0.435 & 0.257 \\
\hline & Low cost of accommodations & 4.35 & 4.28 & 0.001 & 0.435 & 0.257 \\
\hline & Alteration of currency exchange rate & 3.95 & 4.17 & 0.000 & 0.125 & 1 \\
\hline & Inflation rate changes & 3.65 & 4.11 & 0.000 & 0.057 & 0.078 \\
\hline & Long waiting lists in home countries & 4.15 & 4.22 & 0.007 & 1.000 & 0.792 \\
\hline \multirow{3}{*}{$\begin{array}{l}\text { Personal } \\
\text { factors }\end{array}$} & Medical tourists' income rates & 4.55 & 4.67 & 0.000 & 1.000 & 0.705 \\
\hline & Uninsured medical tourists & 4.10 & 4.17 & 0.001 & 1.000 & 1.00 \\
\hline & Family visits for Iranian diaspora & 3.60 & 4.05 & 0.016 & 0.109 & 0.103 \\
\hline \multirow{5}{*}{$\begin{array}{l}\text { Government } \\
\text { support }\end{array}$} & Iran's government support of the medical tourism industry & 4.20 & 4.28 & 0.000 & 0.754 & 0.710 \\
\hline & Ease of obtaining visas & 4.45 & 4.67 & 0.000 & 0.727 & 0.366 \\
\hline & $\begin{array}{l}\text { Facilitate international health care providers and activators in } \\
\text { this industry for competing in international markets } \mathrm{s}^{\mathrm{b}}\end{array}$ & - & 4.61 & - & - & - \\
\hline & $\begin{array}{l}\text { Iran's government avoidance of illegal facilitator's and } \\
\text { brokerages activity for attracting medical tourists }{ }^{\mathrm{b}}\end{array}$ & - & 4.28 & - & - & - \\
\hline & $\begin{array}{l}\text { Integrated management for integrating and organizing all } \\
\text { organizations related to the medical tourism industry }{ }^{\mathrm{b}}\end{array}$ & - & 4.56 & - & - & - \\
\hline \multirow{5}{*}{$\begin{array}{l}\text { Promotional } \\
\text { activities }\end{array}$} & $\begin{array}{l}\text { Advertising Iran's medical tourism industry in the printed and } \\
\text { electronic media markets }\end{array}$ & 4.45 & 4.33 & 0.007 & 0.453 & 0.257 \\
\hline & Branding Iran as a medical tourism destination & 4.15 & 4.67 & 0.000 & 0.289 & 0.157 \\
\hline & Using modern advertisements in internet and social networks & 4.40 & 4.56 & 0.000 & 0.754 & 0.527 \\
\hline & Participating in international exhibitions and conferences & 4.35 & 4.33 & 0.000 & 0.687 & 0.414 \\
\hline & $\begin{array}{l}\text { Advertising Iran's medical tourism industry in international } \\
\text { airports }\end{array}$ & 4.40 & 4.28 & 0.001 & 0.754 & 0.782 \\
\hline \multirow{3}{*}{$\begin{array}{l}\text { Social } \\
\text { security }^{a}\end{array}$} & Providing social security for medical tourists ${ }^{b}$ & - & 4.39 & - & - & - \\
\hline & $\begin{array}{l}\text { Existing supportive rules for supporting foreign travelers from } \\
\text { violation of rights and scams }{ }^{b}\end{array}$ & - & 4.83 & - & - & - \\
\hline & $\begin{array}{l}\text { Providing patients with some regulatory standards through } \\
\text { medical malpractice laws }{ }^{\mathrm{b}}\end{array}$ & - & 4.78 & - & - & - \\
\hline \multirow{2}{*}{$\begin{array}{l}\text { Banking } \\
\text { services }^{\mathrm{a}}\end{array}$} & Solving the problem of bank transactions for foreign tourists ${ }^{b}$ & - & 4.55 & - & - & - \\
\hline & Accepting international credit cards ${ }^{b}$ & - & 4.61 & - & - & - \\
\hline \multirow{3}{*}{$\begin{array}{l}\text { Tourism } \\
\text { attractions }\end{array}$} & Visiting cultural, historical, and natural tourism attractions & 4.65 & 4.00 & 0.000 & 0.152 & 0.317 \\
\hline & Visiting recreational and shopping centers & 4.55 & 4.56 & 0.000 & 1.000 & 1.000 \\
\hline & Visiting therapeutic hot and cold springs ${ }^{b}$ & - & 4.00 & - & - & - \\
\hline \multirow[b]{2}{*}{ Ease of access } & $\begin{array}{l}\text { International airport located in the destination city with flight } \\
\text { schedule to medical tourists' country of residence }\end{array}$ & 4.40 & 4.56 & 0.000 & 1.000 & 0.593 \\
\hline & $\begin{array}{l}\text { Proximity of the destination city to the medical tourists' city of } \\
\text { residence }\end{array}$ & 3.95 & 4.28 & 0.000 & 0.687 & 0.234 \\
\hline \multirow{2}{*}{$\begin{array}{l}\text { Micro-cultural } \\
\text { factors }\end{array}$} & Language similarity with the destination city & 3.90 & 4.05 & 0.000 & 1.000 & 0.417 \\
\hline & Having cultural similarities with the destination city & 3.90 & 4.00 & 0.000 & 1.000 & 0.557 \\
\hline \multirow{3}{*}{ Familiarity } & Medical tourists' previous visits to the destination city & 3.80 & 4.28 & 0.000 & 0.109 & 0.146 \\
\hline & $\begin{array}{l}\text { The role of media advertisements in selecting the destination } \\
\text { city }\end{array}$ & 4.05 & 4.05 & 0.002 & 0.754 & 0.627 \\
\hline & Having friends or relatives in the destination city & 3.80 & 4.17 & 0.000 & 1.000 & 0.204 \\
\hline
\end{tabular}




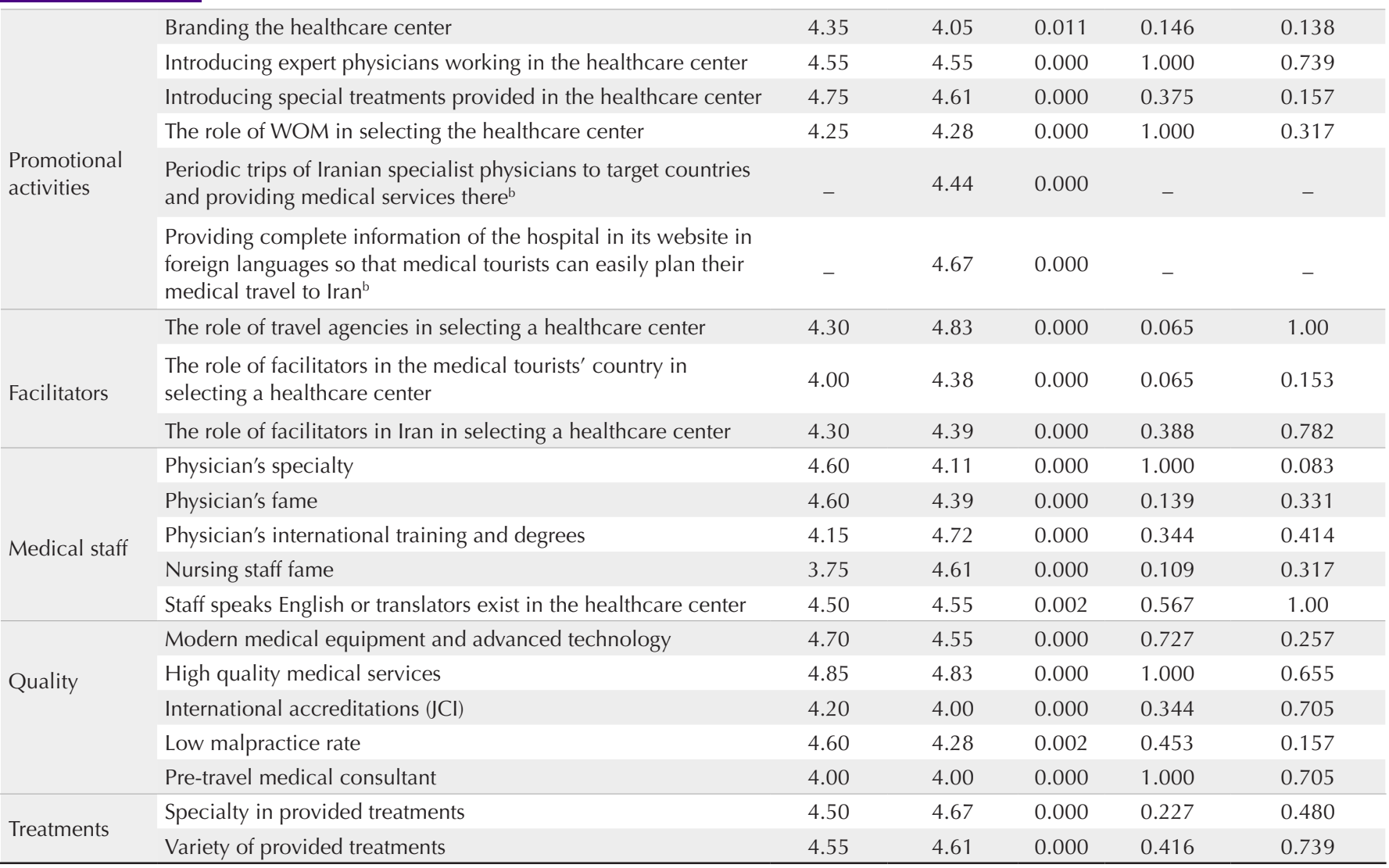

a Explored influencing factors obtained from the Delphi panel.

${ }^{\mathrm{b}}$ Explored variables obtained from the Delphi panel.

$H_{1}: \mu_{1}-\mu_{2} \neq 0$

The results of the nonparametric tests indicated that a $P$ value $\geq 0.05$; thus, the null hypothesis was accepted. It was then concluded that there were no differences between the 2 population means; therefore, a consensus was reached for all questions except those added to the second questionnaire (Table 2). A third round of Delphi was conducted for the added questions. Finally, after 3 rounds of Delphi, the panel members reached a consensus for all questions (Table 3).

By analyzing the data gathered from the Delphi panel, 3 levels of destination selection, each including multiple influencing factors, were obtained. The first level, selecting Iran as a destination country, included medical tourism infrastructure, cultural factors, political and economic conditions, governmental support, personal factors, social security, and banking services as influencing factors. Panel members explored the last 2 influencing factors. The influencing factors for the second level were found to be tourism attractiveness, ease of access, micro-cultural factors, and familiarity. The qualitative approach identified promotional activities, medical staff, quality, treatment variety, and facilitators as influencing factors. In constructing the proposed model, the results of the Delphi panel were combined with the Heung et al supply and demand model..$^{10}$ Two stages of decision-making, i.e. medical tourism and searching information sources, were added from Heung et al's model to the 3-level model of destination selection resulting from the current study. The developed model for selecting Iran as the medical tourism destination is shown in Figure 1. It is noteworthy that this model can be used for other destination countries around the world. This model starts with a medical traveler's decision to travel abroad and is followed by searching different information sources. For selecting Iran as the destination country, one conducts a 3-level decision-making process; in the first stage, factors are evaluated to choose the country; in the second state, the destination city is chosen; and finally, the destination hospital is selected.

\section{Discussion}

Today, medical tourism is a new financial resource for the economic systems of countries. ${ }^{5}$ Policymakers and healthcare providers should recognize the factors that influence the international medical traveler's destination choice. ${ }^{12}$ In the current research, a model was developed for selecting Iran as a medical tourism destination. The main part of this model ( 3 levels of destination selection along with identified influencing factors for each level) is the result of an extensive literature review and expert opinions obtained using the Delphi method. These 3 defined levels are (1) selecting Iran as the destination country, (2) selecting the destination city, and (3) selecting the healthcare center (Figure 1). The discussion below is based on the experts' opinions about the influencing factors identified for each level of medical tourism destination selection.

Factors included in the first level include medical tourism infrastructure, cultural factors, political and economic conditions, governmental support, personal factors, and social security and banking services. There are political 
Table 3. Results of Nonparametric Sign and Wilcoxon Tests for the Third Round

\begin{tabular}{|c|c|c|c|c|}
\hline Variables & $\begin{array}{l}\text { 2nd round } \\
\text { Means }\end{array}$ & $\begin{array}{l}\text { 3rd Round } \\
\text { Means }\end{array}$ & $\begin{array}{l}P \text { Value in } \\
\text { Sign Test }\end{array}$ & $\begin{array}{l}P \text { Value in } \\
\text { Wilcoxon Test }\end{array}$ \\
\hline Religious similarity for Shi'a medical tourists & 4.11 & 4.53 & 0.125 & 0.331 \\
\hline Tendency for pilgrimages for Shi'a medical tourists & 4.05 & 4.46 & 0.125 & 0.331 \\
\hline $\begin{array}{l}\text { Facilitate international health care providers and activators in this industry for competing in } \\
\text { international markets }\end{array}$ & 4.61 & 4.40 & 1.00 & 1.00 \\
\hline $\begin{array}{l}\text { Iran's government avoidance of illegal facilitator's and brokerages activity for attracting } \\
\text { medical tourists }\end{array}$ & 4.28 & 4.46 & 0.125 & 0.331 \\
\hline $\begin{array}{l}\text { Integrated management for integrating and organizing all organizations related to the } \\
\text { medical tourism industry }\end{array}$ & 4.56 & 4.40 & 0.125 & 0.331 \\
\hline Providing social security for medical tourists & 4.39 & 4.60 & 0.250 & 0.083 \\
\hline Existing supportive rules for supporting foreign travelers from violations of rights and scams & 4.83 & 4.73 & 1.00 & 0.564 \\
\hline Providing patients with some regulatory standards through medical malpractice laws & 4.78 & 4.80 & 1.00 & 1.00 \\
\hline Solving the problem of bank transactions for foreign tourists & 4.55 & 4.66 & 0.625 & 0.317 \\
\hline Accepting international credit cards & 4.61 & 4.73 & 0.289 & 0.157 \\
\hline Visiting therapeutic hot and cold springs & 4.00 & 4.06 & 1.00 & 1.00 \\
\hline $\begin{array}{l}\text { Periodic trips of Iranian specialist physicians to target countries and providing medical } \\
\text { services there }\end{array}$ & 4.44 & 4.53 & 1.000 & 0.705 \\
\hline $\begin{array}{l}\text { Providing complete information of the hospital in its website in foreign languages so that } \\
\text { medical tourists can easily plan their medical travel to Iran }\end{array}$ & 4.67 & 4.60 & 1.00 & 0.564 \\
\hline
\end{tabular}

and social obstacles in Iran that weaken the success of the medical tourism industry. Experts believe that these obstacles exist because of the lack of suitable government support, the political climate, ${ }^{15}$ and the lack of social security and banking services. Iran's medical tourism industry needs more support from the government in terms of planning and marketing, providing legal permission to facilitators to bring medical tourists to the country, and facilitating Iran's medical tourism industry through a more flexible visa process. ${ }^{6}$ While conducting this study, the researchers discovered that none of the travel agencies, however they are facilitating medical tourism, had legal permission to attract and guide medical tourists to Iran. In this atmosphere, the demand for medical tourism in Iran by citizens of neighboring countries and the high income gained from bringing medical tourists to the country provides the means for illegal facilitators and brokerages to play a significant role in guiding foreign patients. In some cases, the activity of illegal facilitators leads to scams and violations of rules, not guiding medical tourists to the proper hospitals and doctors.

The economic and political conditions in Iran arisen after sanctions were imposed made other destinations ${ }^{15}$ such as India, Turkey, and Jordan more favorable for the region's medical tourists. Providing banking services to foreign travelers is an important problem in Iran. After the imposition of sanctions, Iranian banks faced many problems, including making bank transactions with other international banks and accepting international credit cards. Therefore, medical tourists are forced to transport cash with them, which increases the probability of robbery. Overcoming such problems may convince medical tourists that travel to Iran is safe and allow them to pay their accommodation and medical expenses more easily. Providing social security in case of regulatory rules and standards is necessary in attracting medical tourism. Such rules will support medical tourists in case of scams or medical malpractice and give them social security.

In the absence of promotional activities, the government and organizations related to the medical tourism industry must enhance their cooperation and coordination for planning and promoting this industry. Extending target markets and developing Iran's medical tourism industry should be promoted and introduced as a brand in the global market. Decision-makers must put all their efforts into creating a reliable and favorable ${ }^{14}$ medical tourism brand in Iran.

In the second level of medical tourism destination selection, "the domestic tourist marketplace needs to be highly competitive by emphasizing on place awareness and identify the opportunities a place has to offer." ${ }^{14}$ The cities of Isfahan, Shiraz, and Yazd, in addition to being possible medical tourism cities, are internationally famous for their heritage attractions, and Mashhad, another possible choice of medical tourists, is famous for its pilgrimage opportunities. However, domestic promotional activities should take place to introduce the cultural/heritage, natural tourism attractions and medical centers that provide medical services to medical travelers in all candidate cities.

In the third level of medical tourism destination selection are medical centers which have an important role in promoting their center, staff, and services. Gaining JCI accreditations could increase the notice given to Iranian medical centers by medical tourists.

Iran's distinctive advantages in the medical tourism industry include lower medical costs, high quality medical services, qualified and expert physicians, and tourist attractions. $^{30}$ However, Iran's target market consists of neighboring countries; it has not been successful in attracting medical tourists from developed countries. In recent years, with the development of the medical tourism industry in other regional countries, such as Turkey, Jordan, and the UAE (having numerous JCI-accredited hospitals), Iran has lost its neighboring countries' market to competitors. Experts believe 


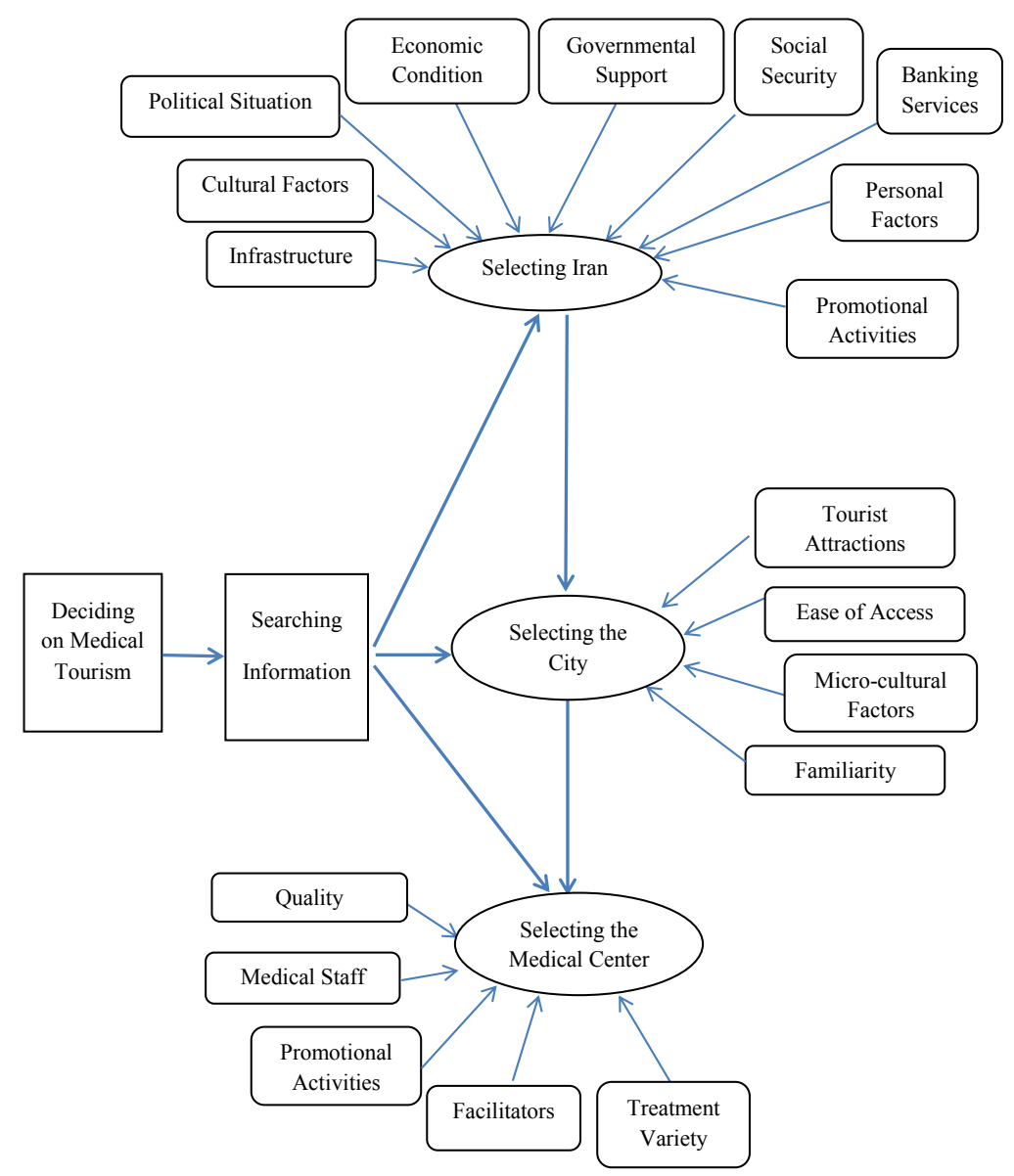

Figure 1. A Multilevel Model for Choosing Iran as the Medical Tourism Destination.

that removing all of the above-mentioned constraints would help the development of Iran's medical tourism industry.

The findings of this study could be critical for decisionmakers and healthcare providers, since they play significant roles in developing this industry through branding Iran as a reliable medical tourism destination. It is hoped that the Iranian government, related organizations, and all healthcare providers in Iran will consider this model in developing their planning and marketing programs and gain a substantially higher market share in the region.

\section{Conclusion}

The gap in research literature about destination choice in the field of medical tourism concerned the lack of a multilevel model that included choosing a destination city. The current research constructed a model that will aid in understanding a country's strengths and weaknesses in the medical tourism market; this study focused on Iran, a country that has many strengths but poor promotional activities in branding itself as a medical tourism hub. This study recognized a separate level for choosing a destination city which was not previously identified. Therefore, the model presented by this study for evaluating influencing factors related to each level of the destination selection is the novelty of this study. This model suggests that each factor in every level plays an important role in a medical tourist's decision; however, to prioritize these factors, the attitudes of medical tourists toward these influencing factors should be evaluated in further research. The constructed model (Figure 1) could be used as a base for future strategic planning and marketing research in improving Iran's medical tourism industry and gaining a substantially higher market share in the region. Different factors are influential in each level. The first level mostly includes factors related to the government, such as the political and economic situation, banking services, etc. Medical tourists from developed countries consider these factors in choosing a destination country ${ }^{9}$; thus, the government plays an important role in attracting more medical tourists to Iran. The government and organizations related to the medical tourism industry must enhance their cooperation in planning and promoting this industry. Target markets should be extended, and Iran's medical tourism industry should be promoted and introduced in the global market. In the third level of selection are the medical centers which have an important role in promoting their center, staff, and services. Gaining JCI accreditations could increase the attention given by medical tourists to Iranian medical centers. It is hoped that the Iranian government, related organizations, and all of the healthcare providers in Iran would consider this model in developing their planning and marketing programs.

\section{Authors' Contributions}

All authors contributed equally to the preparation of this paper.

\section{Conflict of Interest Disclosures}

The authors declare that they have no conflicts of interest. 


\section{Ethical Approval}

The data presented in this study is the result of the authors' research in this area; the authors confirm that the data was not published previously.

\section{Funding/Support}

No funding was received for this research.

\section{Acknowledgments}

This paper has been extracted from a $\mathrm{PhD}$ dissertation. The authors would like to warmly thank all of the Delphi panel members who helped us to accomplish this study, especially Dr. Saffari from Basir Ophthalmology Clinic.

\section{References}

1. Kumar GS, Raj RK. Status, growth and impact of medical tourism in India. Int J Pharm Sci Rev Res. 2015;34(1):284-291.

2. Connell J. Contemporary medical tourism: conceptualisation, culture and commodi. Tour Manag. 2013;34:1-13.

3. Turner L. "Medical tourism" and the global marketplace in health services: U.S. patients, international hospitals, and the search for affordable health care. Int J Health Serv. 2010;40(3):443-467. doi:10.2190/HS.40.3.d.

4. Moghimehfar F, Nasr-Esfahani MH. Decisive factors in medical tourism destination choice: a case study of Isfahan, Iran and fertility treatments. Tour Manag. 2011;32(6):1431-1434.

5. Gholami M, Jabbari A, Kavosi Z, Gholami M. Service quality in iran's medical tourism: hospitals in Shiraz city. Int J Travle Med Glob Health. 2016;4(1):19-24. doi:10.20286/ijtmgh-040119

6. Asadi R, Daryaei M. Strategies for development of Iran health tourism. Eur J Soc Sci. 2011;23(3):329-344.

7. Izadi M, Ayoobian A, Nasiri T, Joneidi N, Fazel M, Hosseinpourfard M. Situation of health tourism in Iran; opportunity or threat. Mil Med J. 2012;14(2):69-75.

8. Jabbari A, Zarchi MR, Kavosi Z, Shafaghat T, Keshtkaran A. The marketing mix and development of medical tourism in Shiraz. Mater Sociomed. 2013;25(1):32-36. doi:10.5455/msm.2013.25.32-36.

9. Smith P, Forgione DA. Global outsourcing of healthcare: a medical tourism decision model. Journal of Information Technology Case and Application Research. 2008;9(3):19-31. doi:10.1080/15228 053.2007.10856117.

10. Heung VCS, Kucukusta D, Song H. A conceptual model of medical tourism: implications for future research. Journal of Travel and Tourism Marketing. 2010;27(3):236-251. doi: $10.1080 / 10548401003744677$

11. Hueng VCS, Kucukusta D, Song H. Medical tourism development in Hong Kong: an assessment of the barriers. Tour Manag. 2011;32:995-1005.

12. Dehdashti ZS, Nakhaei HK. An entropy (Shannon) based approach for determining importance weights of infuencing factors in selecting medical tourism destination. Int J Travel Med Glob Health. 2016;4(4):115-121. doi:10.21859/ijtmgh-040406.

13. Fetscherin $M$, Stephano RM. The medical tourism index: Scale development and validation. Tour Manag. 2016;52:539-556.

14. Foroudi P, Gupta S, Kitchen P, Foroudi MM, Nguyen B. A framework of place branding, place image, and place reputation: antecedents and moderators. Qualitative Market Research: An International Journal. 2016;19(2):241-264. doi:10.1108/QMR-02-2016-0020.

15. Manouchehri J, Farhangi AA, Someeh S, Shakibaei E. The challenges of Kish health tourism: A case study. Int J Basic Appl Sci. 2014;3(3):335-343.

16. Hajinejad A, Eslamfard F. Formulating Strategies for the development of treatment tourism in Shiraz (Iran) using a strategic planning approach (SWOT). J Rafsanjan Univ Med Sci. 2013;12(8):641-654. [Persian].

\section{Research Highlights}

\section{What Is Already Known?}

Medical tourism is a fast-growing industry with economic advantages for destination countries. Iran as a medical tourism destination benefits from its potentials such as expert and famous physicians, modern medical technology, advanced medical research, and its natural and cultural tourism attractions.

\section{What This Study Adds?}

This study suggests a multilevel model for choosing Iran as a medical tourism destination. Despite other medical tourism destinations, Iran has the advantage of providing international medical services in different cities known as medical tourism hubs which can cover all the medical needs of its neighboring countries. The model proposed by this study considers all the influencing factors in the three levels of selecting Iran as the destination country, selecting the destination city, and selecting the healthcare center. Consumption and post-consumption behavior have been considered in this model as well.

17. Ye BH, Yuen PP, Qui HZ, Zhang VH. Motivation of medical tourists: an exploratory case study of Hong Kong medical tourists. PTA Annual Conference; 2008; Bangkok, Thailand.

18. Leng $\mathrm{CH}$. Medical tourism in Malaysia: international movement of healthcare consumers and the commodification of healthcare. Asia Research Institute Working Paper Series No. 83; 2007.

19. Dwyer L, Kim C. Destination competitiveness: determinants and indicators. Current Issues in Tourism. 2008;6(5):369-414. doi:10.1080/13683500308667962

20. Alsharif M, Labonte R. Patients beyond borders: a study of medical tourists in four countries. Glob Soc Policy. 2010;10:315-335. doi:10.1177/1468018110380003.

21. Ghanbari S, Hajinejad A, Rahmani P. Formulating strategic plan of medical tourism development. Int J Travlel Med Glob Health. 2014;2(4):149-154.

22. Saadatnia F, Mehregan MR. Determining and prioritizing factors affecting to increase customers attraction of medical tourism from the perspective of Arabic countries. Int J Mark Stud. 2014;6(3):155.

23. Ehrebeck T, Guevara C, Mango PD, Cordina R, Singhal S. Health care and the consumer. McKinsey Quarterly. 2008;4:80-91.

24. Yu JY, Ko TG. A cross-cultural study of perceptions of medical tourism among Chinese, Japenese and Korean tourists in Korea. Tour Manag. 2012;33:80-88. doi:10.1016/j.tourman.2011.02.002.

25. Connell J. Medical tourism: sea, sun, sand and... surger. Tour Manag. 2006;27(6):1093-1100. doi:10.1016/j.tourman.2005.11.005.

26. Lunt N, Smith RD, Mannion R, et al. Implications for the NHS of inward and outward medical tourism: a policy and economic analysis using literature review and mixed-methods approaches. Health Serv Deliv Res. 2014;2(2):262.

27. Hallowell MR, Gambatese JA. Qualitative research: application of the Delphi method to CEM research. J Constr Eng Manag. 2010;136(1). doi:10.1061/(ASCE)CO.1943-7862.0000137.

28. Lang T. An Overview of Four Futures Methodologies (Delphi, Environmental Scanning, Issues Management and Emerging Issue Analysis). http://158.132.155.107/posh97/private/research/ methods-delphi/LANG.pdf.

29. Anderson DR, Sweeney DJ, Williams TA. Statistics For Business And Economics. Cincinnati: South Western, Thomson Learning Publishing; 2002.

30. Blalock HM. Social Statistics. Singapore: McGraw-Hill; 1979. 